\title{
Oligodendrocyte development in the embryonic brain: the contribution of the plp lineage
}

\author{
BARBARA LE BRAS, ELLI CHATZOPOULOU, KATHARINA HEYDON, SALVADOR MARTÍNEZ1 , KATZUHIKO \\ IKENAKA ${ }^{2}$, LAETITIA PRESTOZ ${ }^{3}$, NATHALIE SPASSKY, BERNARD ZALC and JEAN-LÉON THOMAS* \\ Unité Mixte de Recherche INSERM U-711 \& UPMC, Paris, France, 'Instituto de Neurociencias, Universidad Miguel Hernandez, San Juan \\ de Alicante, Spain, ${ }^{2}$ National Institut for Physiological Sciences, Okazaki National Research Instituts, Okazaki, Aichi, Japan and \\ ${ }^{3}$ PBS- Laboratoire des Biomembranes et Signalisation Cellulaire, Université de Poitiers, France.
}

\begin{abstract}
Oligodendrocytes are the myelin forming cells of the central nervous system. Over the last decade, their development in the embryonic brain and spinal cord has been documented following the discovery of early oligodendroglial markers. This review highlights the fundamental results obtained on the specification and migration of oligodendroglial cells and illustrates our advances in the knowledge of the cell lineage expressing p/p (proteolipid protein), one of the early oligodendroglial genes.
\end{abstract}

KEY WORDS: embryonic brain, oligodendrocyte, specification, migration, plp/dm-20

\section{Introduction}

The nervous system is constituted of two major cellular families: neurons, which are interconnected in networks to form electrically active circuitry and glial cells, the functions of which still remain in large to be fully elucidated. For long, glia has been assimilated to the connective cell type of the nervous tissue and its function restricted to that of supporting cells, responsible for the nutrition and insulation of neurons. Ongoing observations and experimental arguments, however, provide evidence that glial cells may have a more active role in the structural and functional plasticity of the nervous system. In this respect, it is striking to note that during evolution there is a gradual increase in the proportion of glial cells. In invertebrates, like the fly or nematode, glial cells account for 25$30 \%$ of total nervous system cells. This percentage increases to $60-70 \%$ in rodents and has been claimed to reach $90 \%$ in humans (Pfrieger and Barres, 1995). Glia is subdivided in macroglia (astrocytes, oligodendrocytes and ependymal cells), which like neurons is derived from the neuroectoderm and microglia, which results from the invasion of cerebral tissue by circulating monocytes. Our studies concern the oligodendrocytes which are the myelin forming cells of the central nervous system (CNS). Myelin is specific to vertebrates and facilitates nerve conduction. Consequently, the degree of motor maturation at birth reflects the extent to which myelination has advanced during embryonic development. In the adult, the oligodendrocytes are affected by one main neurological disease: Multiple sclerosis (MS), a frequent and invalidating disease of the young adult. MS is characterised by an inflammatory reaction, probably of an autoimmune type and a demyelination frequently associated with a loss of oligodendrocytes. To date, the available treatments can suppress the inflammation, but have little, if any, efficacy on remyelination. The identification of molecular factors controlling oligodendroglial differentiation, migration and myelination appears thus as a priority to positively influence a remyelination of the lesions. With this perspective in mind, we are investigating the cellular and molecular aspects of oligodendrogenesis and focus our studies on the embryonic brain due to the similarity of mechanisms involved in the differentiation of embryonic neural cells and stem cell populations of the adult brain.

Studies on the origin of oligodendrocytes have long been hampered by the lack of recognized markers of their precursors. We have identified one of the markers of oligodendrocyte precursor cells (OPCs), the plp/dm-20 transcripts (Timsit et al., 1995; Spassky et al., 1998, 2001a-b; Perez-Villegas et al., 1999). PLP/ $d m-20$ belongs to the $d m$ family of genes whose members have been identified in the shark, the ray (Kitagawa et al., 1993) and the mouse (Yan et al., 1993). Plp encodes two alternative spliced products: the proteolipid protein (PLP) and DM-20, which are proteins with four putative transmembrane domains (Popot et al., 1991) and are the major protein components of higher CNS myelin

Abbreviations used in this paper: opc, oligodenrocyte precursor cell; plp, proteolipid protein.

\footnotetext{
*Address correspondence to: Dr. Jean-Léon Thomas. Unité Mixte de Recherche INSERM U-711 \& UPMC, Hopital de la Salpltrière, 75651 Paris Cedex 13, France. Fax: +33-1-4584-8008. e-mail: jlthomas@ccr.jussieu.fr
} 
(Lees and Brostoff, 1984). Although PLP is expressed during the final stages of oligodendrocyte maturation, the corresponding transcripts can be detected much earlier during embryonic development (Timsit et al., 1992). Moreover, the presence of restricted subsets of $p / p^{+}$neuroepithelial cells in the mouse embryonic brain and spinal cord suggested a link between $p / p$ expression and early oligodendrogenesis (Timsit et al., 1995; Dickinson et al., 1996).

We have thus investigated the cell fate of the $p / p$ lineage. Their specification and migration have been analyzed both in chick and mouse species and we have searched for molecules guiding $p / p^{+}$ OPC migration from the ventricular foci towards the future white matter tracts. The resulting findings were: i) a spatio-temporal description of oligodendrogenesis and OPC migratory pathways in the mouse and chick embryonic brain (Spassky et al., 1998, 2001b; Perez-Villegas et al., 1999; Olivier et al., 2001); ii) the characterization of $p / p^{+}$OPCs as PDGF-A independent precursors, thus distinct from PDGFR $\alpha$ expressing OPCs (Spassky et al., 2001a); iii) the identification of molecules controling OPC migration, some of which act from a distance, like the axonal guidance molecules class 3 semaphorins and netrin-1 (Spassky et al., 2002), while others mediate their effect by a direct cell to cell contact, like the ephrinB2 ligand (Prestoz et al., 2004).

\section{Results}

$\mathrm{plp} / \mathrm{dm}-20$ is expressed by restricted progenitor domains generating neurons and oligodendrocytes

To provide evidence that p/p/dm-20 expressing cells in the germinative neuroepithelium are precursors that give rise to oligodendrocytes, we have generated a transgenic murine line where a zeomycin resistance gene fused to the lac $Z$ reporter was expressed under the control of the $p / p$ - regulatory sequences (Figure 1A). The pattern of $\beta$-galactosidase expression was similar and superimposable on the expression pattern of of endogenous plp/dm-20. At E12.5, the transgene was expressed predominantly in restricted domains of the ventral neural tube, in the ganglionic eminence, the basal plate of the caudal hypothalamus, diencephalon and rhombencephalon, with the exception of the rhombomeres $r 3$ to $r 5$ (Figure $1 \mathrm{~B}$ ). Both in vivo and in vitro, the transgene was expressed by $\mathrm{O}^{+}$pre-oligodendrocytes and later by differentiated oligodendrocytes, but not by neuronal cells (Figure 1C), astrocytes, or radial glial cells. In cultures derived from E12.5 transgenic embryos, a dramatic enrichment in $\mathrm{O}^{+}$pre-oligodendrocytes was observed following zeomycin selection (Figure 1D), whereas in control cultures double labeled cells $\left(\mathrm{O}^{+} / \mathrm{Xgal}^{+}\right)$represented only $15-20 \%$ of the total population. The enrichment in the $\mathrm{O}^{+}$preoligodendrocytes, following zeomycin treatment of cultures derived from rostral and caudal territories of the brain anlage, indicate that, in both regions, neural precursors expressing $p / p / d m-20$ cells give rise to oligodendrocytes.

In the CNS, the plp gene was first detected at E9.5 in the basal plate of the diencephalon, the caudal hypothalamus and the entopeduncular area in the ventrocaudal region of the telencephalon. This early $p / p$ expression coincides with an active period of neurogenesis in the neuroepithelium, which suggested that $p / p$ progenitors might be pluripotent cells, not restricted to an oligodendroglial fate. To examine the differentiation potential of $p / p+$ progenitors emerging at early stages of neural tube development (E9.5-10.5), we used transgenic p/p-GFP mice in

A

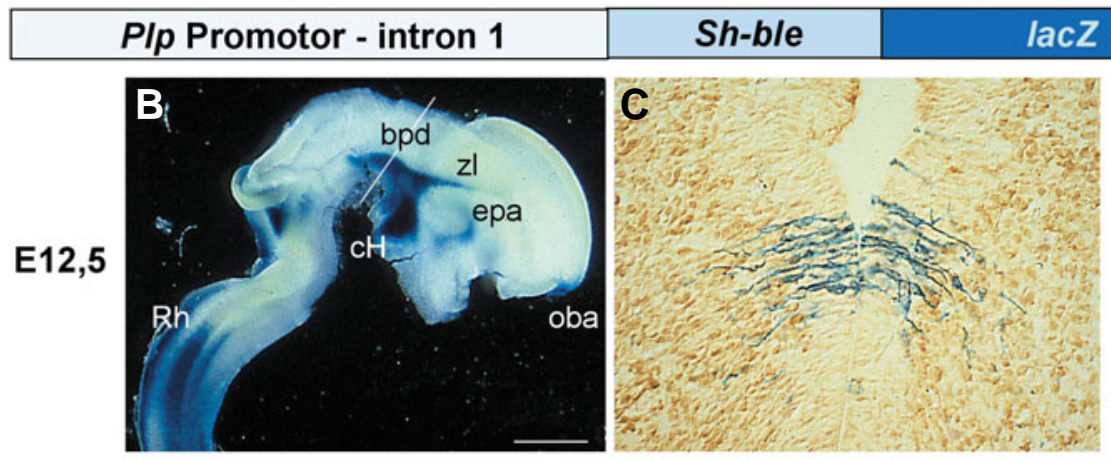

D

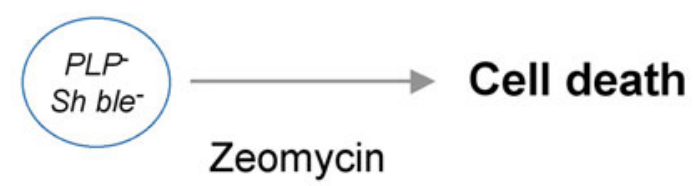

Fig. 1. The plp-shble-lacZ murine transgenic line. (A) The promotor and regulatoty sequences of plp gene (Wight et al., 1993) drive the expression of sh ble, a gene isolated from Streptoalloteichus hindustanus, which confers resistance to the antibiotics phleomycin and zeomycin, in frame with the E. coli lacZ reporter gene, which allows an easy detection of transgene expressing lines. (B,C) Reporter gene expression in E12.5 plp-sh blelacZ embryonic brain. (B) From rostral to caudal, note the expression in the prospective olfactory bulb (pob), the anterior entopeduncular area (epa), the caudal hypothalamus $(\mathrm{cH})$, the basal plate of diencephalon (bpd) and the basolateral plate of rhombencehalon (Rh). (C) Coronal section at the diencephalic level in (B), illustrating the restricted localization of plp expressing cells in the ventricular neuroepithelium (in blue), distinct from the $\mathrm{Hu}^{+}$neurons distributed in the surrounding mantle layer (in brown). Scale bar (shown in (B): B, $720 \mu \mathrm{m} ;$, $70 \mu \mathrm{m}$. (D) In vitro, zeomycin treatment results in the selection of plp'expressing neuroepithelial cells from the diencephalic plate of E12.5 plp-sh ble-lacZ embryos. After 9 days in vitro, the large majority of transgene expressing cells in culture are $\mathrm{O4}^{+}$pre-oligodendrocytes. In vitro, E12.5 plp progenitors thus show a potentiality to generate oligodendrocytes. Reprinted from Spassky et al. (1998), with permission from The Society for Neuroscience. 


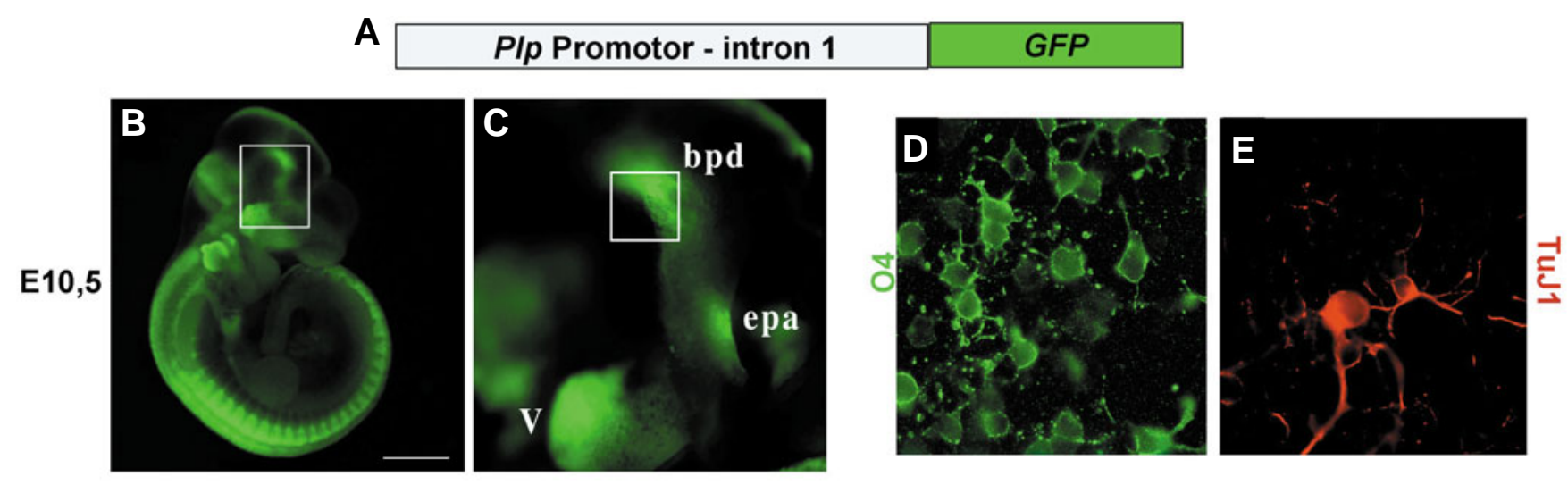

FACS + 15 DIV

Fig. 2. The plp-GFP murine transgenic line. (A) The plp promotor and regulatory sequences are in frame with the reporter gene EGFP. (B,C) Reporter gene expression in a E10.5 plp-GFP embryo. Note the expression of transgene in peripheral nervous system derivatives of the neural crest and, in the CNS, in the entopeduncular area (epa) and the basal plate of diencephalon (bpd). (C) Enlargment of the boxed area in (B). Scale bar (shown in B): B, 380 $\mu \mathrm{m} ; \mathrm{C}, 110 \mu \mathrm{m} ; \mathrm{D}, \mathrm{E} 50 \mu \mathrm{m}$. (D,E) FACS sorted cells from the diencephalic basal plate of E10.5 plp-GFP embryos, cultured on a feeder layer of astrocytes and $1 \%$ fetal calf serum, differentiate into $\mathrm{O}^{+}$oligodendrocytes (D) and TuJ1+ neurons (E) after 15 days in vitro. Under these culture conditions, E10.5 plp progenitors are thus specified towards the neuro-oligodendroglial lineages. Reprinted from Spassky et al. (2001b), with permission from Karger.

which expression of the GFP reporter gene is driven by the $p / p$ regulatory sequences (Figure $2 \mathrm{~A}, \mathrm{~B})$. Living $p / p+$ progenitors were isolated from E9.5-10.5 diencephalic basal plate (Figure $2 \mathrm{C}$ ) by fluorescence-activated cell sorting (FACS) and cultivated on a feeder layer of astrocytes in DMEM enriched with $1 \%$ foetal calf serum during 15 days in vitro. The presence of neurons and glial cells was then tested by immunohistochemistry. One half of the cells derived from $p / p-G F P_{+}$progenitors was composed of differentiated cells: $5 \%$ of TuJ1+/GFP negative neurons (Figure 2D) and $45 \%$ of $\mathrm{O}_{+}+\mathrm{GFP}^{+}$oligodendrocytes (Figure $2 \mathrm{E}$ ), but no astrocytes. The other half of the cells in culture were nestin+ and did not express any differentiated phenotype. In contrast, neurons, oligodendrocytes and astrocytes were obtained from the $p / p$-GFP negative population sorted by FACS. These results suggest a neuro-oligodendroglial bipotentiality of the population of $p / p+$ progenitors. They also demonstrate that $p / p$ expression is downregulated in the neuronal progeny of $p / p^{+}$progentors while it is maintained in the oligodendroglial progeny.

plp/dm-20 progenitors generate PDGFR $\alpha$ independent-OPCs

Although $p / p / d m-20$ progenitors generate oligodendrocytes, they do not represent the totality of cells capable of generating oligodendrocytes in the embryonic brain. At E12.5, some p/p/dm20- neuroepithelial territories have the potential to generate oligodendrocytes in vitro. Interestingly, these $p / p / d m-20$-territories expressed the transcripts of platelet derived growth factor receptor alpha (PDGFR $\alpha$ ), another early marker of the oligodendroglial lineage (Pringle et al., 1993; Yu et al., 1994). In the hindbrain and spinal cord, as well as in the medial ganglionic eminence of the telencephalon, both transcripts are present, but co-expression at the cellular level is only detected in very rare cells of the ventricular layer (less than $10 \%$ in the entopeduncular area of E5.5 chick embryo). In the diencephalon and midbrain, the expression of PDGFR $\alpha$ and $p / p / d m-20$ alternated. In the olfactory bulb, at E14.5,
PDGFR $\alpha$ was not detected, in contrast to $p / p / d m-20$ which was expressed by subsets of ventricular progenitors (Figure 3A). These observations suggested that oligodendrocytes could derive from at least two distinct types of progenitors expressing either $p / p / d m-20$ or PDGFR $\alpha$. To determine whether $p / p / d m-20$ and PDGFR $\alpha$ progenitors were lineage-linked or not, we followed the development of $p / p / d m-20$ progenitors in the absence of PDGFR $\alpha$ signalling. Dissociated cell cultures, derived from either the ganglionic eminences or the anlage of the olfactory bulb (E12.5), were performed in the presence of a tyrosine kinase inhibitor STI571 (Gleevec) specific for the PDGFR $\alpha$ (Figure 3B). In olfactory bulb cultures, the survival and proliferation of $p / p / d m-20$ progenitors, as well as their differentiation into $\mathrm{O}^{+} / \mathrm{GalC}^{+}$oligodendrocytes were not affected by blocking the PDGFR $\alpha$ signalling. In contrast, oligodendrogenesis from the ganglionic eminence was reduced by half in the presence of STI571. These data provided strong evidence that $p / p / d m$ - 20 progenitors do not depend on signal transduction mediated by platelet derived growth factor receptors (PDGFR). Therefore, $p / p / d m-20$ cells most probably belong to a lineage different from the PDGFR $\alpha$ expressing progenitors and oligodendrocytes of the embryonic brain have a multiple origin.

\section{Regional identity of oligodendrocyte migrations in the embryonic brain}

To establish the topological relationship between the ventricular foci of oligodendrocyte progenitors and the different populations of brain oligodendrocytes, we have turned to the avian model. The avian embryo is indeed accessible at all stages of development, which allows to generate neural chimeras (LeDouarin, 1969, 1993). In the chick embryonic brain, as in the mouse, $p / p / d m-20$ was expressed, from the onset of neurogenesis (E2.5), in restricted foci of the ventral neuroepithelium (Figure 4A). From E5-6, the p/p/ $d m-20$ cells expanded in the mantle layer (Figure 4B) and $4^{+}$cells delaminated from the ventricular foci of $p / p / d m-20$ progenitors 
A

E14.5
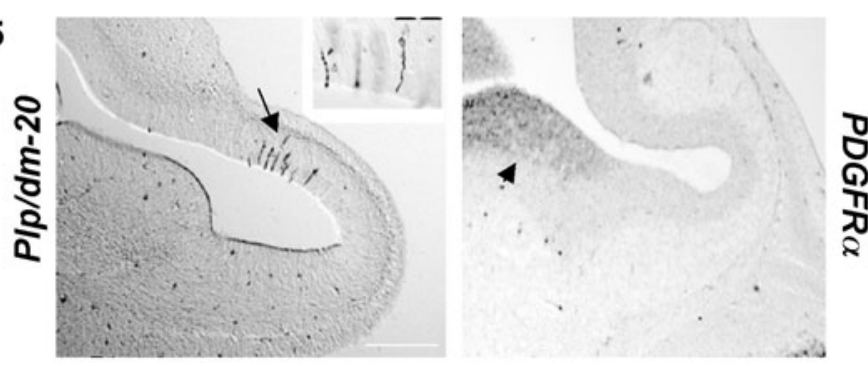

B


Fig. 3. Heterogeneity among oligodendrocyte precursor cells. (A) At $E 14.5$, the patterns of distribution of $\mathrm{plp} / \mathrm{dm}-20$ and PDGFR $\alpha$ cells in the rostro-ventral forebrain are distinct. Using a plp-sh ble-lacZ embryo, plp/dm-20 cells are detected by lacZ expression (left panel) and PDGFR $\alpha$ cells by in situ hybridization (right panel). In the olfactory bulb, plp/dm-20 cells (arrow) are restricted to the ventricular layer (magnification in the insert), where PDGFR $\alpha$ expression is not detectable. In contrast, PDGFR $\alpha$ cells (arrowhead) are abundant in the medial ganglionic eminence (not shown on the left panel). Scale bar: $200 \mu \mathrm{m}$; insert in the left panel, $16 \mu \mathrm{m}$. (B) Blocking PDGFR tyrosine kinase does not interfere with development of $\mathrm{plp} / \mathrm{dm}-20+$ progenitors cells. Olfactory bulb anlage (left panel) or ganglionic eminences (right panel) from E12.5 OF1 wild-type mouse were dissociated, seeded in 96 well dishes and cultivated in BS medium supplemented with 1\% FCS. After 2 days in vitro, either STI571 (50$500 \mathrm{nM})$ or PDGF-AA (10ng/m/) was added. After 13 days in vitro, cultures were immunolabeled with $04 \mathrm{mAb}$ and immunopositive cells were counted. Each column represents the mean + s.e.m of 3 separate experiments representing 14 to 24 different cultures. $\left(^{* *} p<0.0001\right.$; ${ }^{*}$ $p<0.05$, Student's t test). Reprinted from Spassky et al. (2001a), with permission from the Society for Neuroscience.

(Figure 4 C,D). We have established a map of $p / p / d m-20$ expression sites in the chick embryonic brain $(\mathrm{HH} 26)$, which predicts the sites of emergence of oligodendrocytes. These foci of oligodendrogenesis are localized in the baso-ventral plate of the hind-, mid- and caudal fore-brain, while in the rostral forebrain oligodendrocytes emerge from alar territories.

We have then investigated the respective territories colonized by oligodendrocyte progenitor cells originating from either the baso-ventral or alar foci and created a series of quail-chick chimeras. Data from homotopic chimeras demonstrated clearly that, during embryonic development, oligodendrocyte progenitors emerging from the alar anterior entopeduncular area migrate tangentially to invade the entire telencephalon, whereas those from the basal rhombomeric foci show a restricted rostrocaudal distribution and colonize only their rhombomere of origin (Figure 4E). Heterotopic chimeras indicated that differences in the migratory properties of oligodendroglial cells did not depend on their baso-ventral or alar ventricular origin. Irrespective of their origin (basal or alar), oligodendrocytes migrated only short distances in the hindbrain and long distances in the prosencephalon. Furthermore, we showed that, in the embryonic chick brain, all telencephalic oligodendrocytes originate from the anterior entopeduncular area and that the prominent role of anterior entopeduncular area in telencephalic oligodendrogenesis is conserved between birds and mammals.

\section{Diffusible class 3 semaphorins and netrin-1} guide the migration of plp OPCs

Little was known about the endogenous guidance cues controlling the migration of OPCs from their site of emergence towards their final destination, mainly the future white matter tracts. To investigate the molecular control of OPC migration, we chose the embryonic optic nerve as an expertimental system. The embryonic optic nerve has no intrinsic ability to generate oligodendrocytes (Small et al., 1987), but is populated by OPCs originating in the ventral diencephalon (Figure $5 \mathrm{~A}, \mathrm{~B}$ ), which migrate from the chiasm towards the retina (Ono et al., 1997a). In the plp-lac $Z$ mouse, we have monitored the oligodendroglial colonisation of the optic nerve (Figure 5C), which started from E14.5 onwards and filled the nerve to its retinal end at E18.5 (Spassky etal., 2002). In addition, the optic nerve does not contain neuronal cell bodies, which allows a selective analysis of oligodendroglial migration in vitro, either by collagen gel cultures of optic nerve explants (Figure 5D) or by stripe assays on dissociated cell cultures (Figure 5E).

Since neurons and OPCs share common sites of origin in the embryonic neural tube and further develop with close timing, we first postulated that OPC migration might be influenced by the axonal environment, notably the diffusible factors that contribute to guide the axonal guidance. Chemotactic factors of the semaphorin (Messersmith et al., 1995) and netrin (Serafini et al., 1994) families are expressed in the CNS and control the guidance of axonal growth cones (Goshima et al., 2002; Raper, 2000). Some of them have also been implicated in the migration of neural cells. This is the case for Sema 3A, which has a chemorepulsive effect on neural crest cells (Eickholt et al., 1999), Sema 3A and Sema 3F which repel cortical interneurons (Marln et al., 2001) and for netrin-1 which guides the migration of precerebellar, cerebellar 
and hypothalamic neurons (Manitt and Kennedy, 2002). Therefore, we questioned whether semaphorins and netrin molecules could not only act on neurons, but also on glial cells.

We examined the possible role of signalling molecules, such as class 3 semaphorins and netrin-1, on the migration of OPCs. We showed that OPCs migrating into the embryonic optic nerve express the semaphorin receptors neuropilin-1 and -2, as well as DCC (deleted in colorectal cancer) and, to a lesser extent unc $5 \mathrm{H} 1$, two of the netrin-1 receptors. Using collagen gel cultures as a functional migration assay, we provided evidence that Sema 3A and netrin-1 exerted opposite chemotactic effects, repulsive or attractive respectively, on embryonic OPCs. In addition, we showed that Sema 3F had a dual, chemoattractive and mitogenic, effect on embryonic OPCs. The localization of cells expressing Sema 3A, Sema 3F and netrin-1 was consistent with a role for these ligands in the migration of OPCs in the embryonic optic nerve (Figure 6). Altogether, these findings suggest that the migration of OPCs in the embryonic optic nerve is modulated by a balance of effects mediated by members of the semaphorin and netrin families.

\section{Eph/ephrin interactions modulate the axonophilic migration of plp OPCs}

The migration of oligodendrocyte precursors cells (OPCs) is modulated by secreted molecules in their environment (see above) and by cell-cell and matrix-cell interactions. We thus asked whether membrane-anchored guidance proteins such as the ephrin ligands and their Eph receptors could participate in the control of OPC migration in the optic nerve.

The ephrin ligands and their Eph receptors are known as the largest group of receptor tyrosine kinases involved in neural development (Wilkinson, 2001), especially in modulation of axon



C

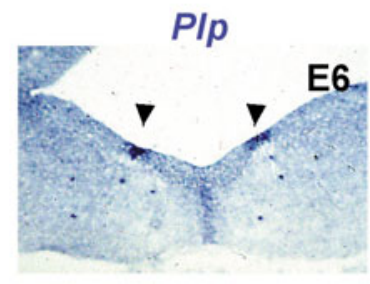

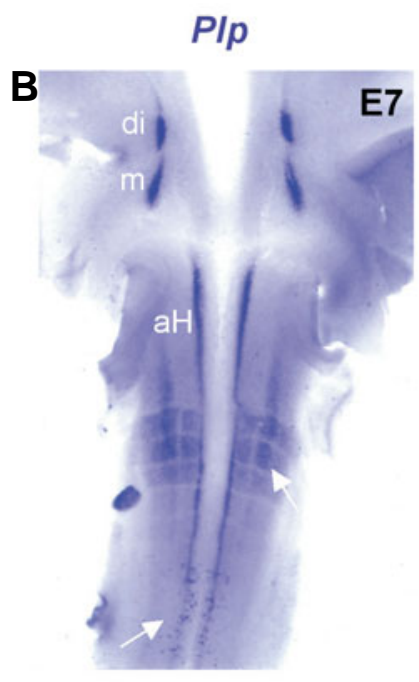

D

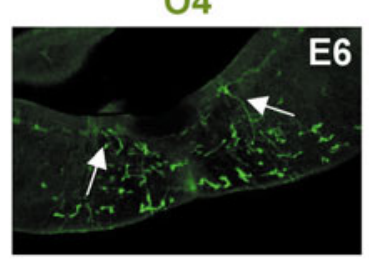

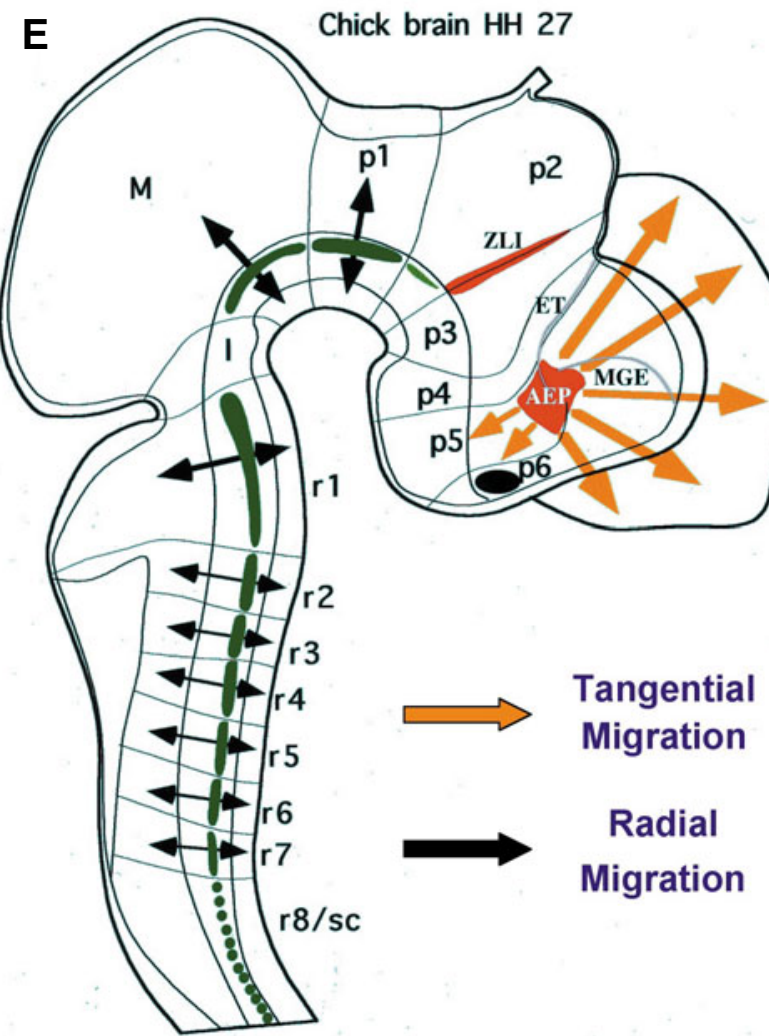

Fig. 4. Regional identity of OPC migrations in the chick embryonic brain. (A-D). Pattern of plp expression of and oligodendroglial development in the embryonic brain. In situ hybridizations were performed with plp $(A, B)$ and sonic hedgehog $(A)$ antisense riboprobes on flat mounts (A,B) and coronal section (C) of the brain. Immunolabeling with the pre-oligodendrocyte marker $\mathrm{O} 4$ was performed on a coronal section of rhombomere 1 (D), adjacent to (C). (A) At E3, restricted foci of plp progenitors (in blue) are localized ventrally in the hindbrain neuroepithelium, close to the source of Sonic hedgehog in the floor plate (in red). (B) At E7, the pattern of plp expression is still restricted to the ventral neuroepithelium in the diencephalon (di), mesencephalon (m) and anterior part of the hindbrain (aH), but cells expand laterally in the mantle layer of more caudal rhombomeres (arrows). (C-D) At E6, in the anterior hindbrain, the foci of plp/dm-20 progenitors (arrowheads in c) are facing the $\mathrm{O}^{+}$pre-oligodendrocytes which migrate and expand in the mantle layer (arrows in D). (E) Model of spatial development of oligodendrocytes in the avian developing brain. Sagittal representation of the brain at stage HH 27 (E56). In the ventricular layer, the basoventral territories of emergence are colored in green, the alar domains in red. Arrows indicate the migratory pathways. Note that oligodendrocyte progenitors emerging from the basoventral foci, in the epicordal domain of the brain, migrate radially (black arrows), while those arising from the alar plate, in the precordal domain of the brain, follow extensive tangential migratory pathways (orange arrows). AEP: anterior entopeduncular area; ET: eminentia thalami; I: Isthmus; M: mesencephalon; MGE: medial ganglionic eminence; p: prosomere (p1 to p6); r: rhombomere ( $r 1$ to r7), sc: spinal cord; ZLI: zona limitans intrathalamica. Scale bar (shown in A): A, $30 \mu \mathrm{m} ; B, 80 \mu \mathrm{m} ; C, D, 270 \mu \mathrm{m}$. Reprinted from Perez-Villegas et al. (1999), with permission from Elsevier. 

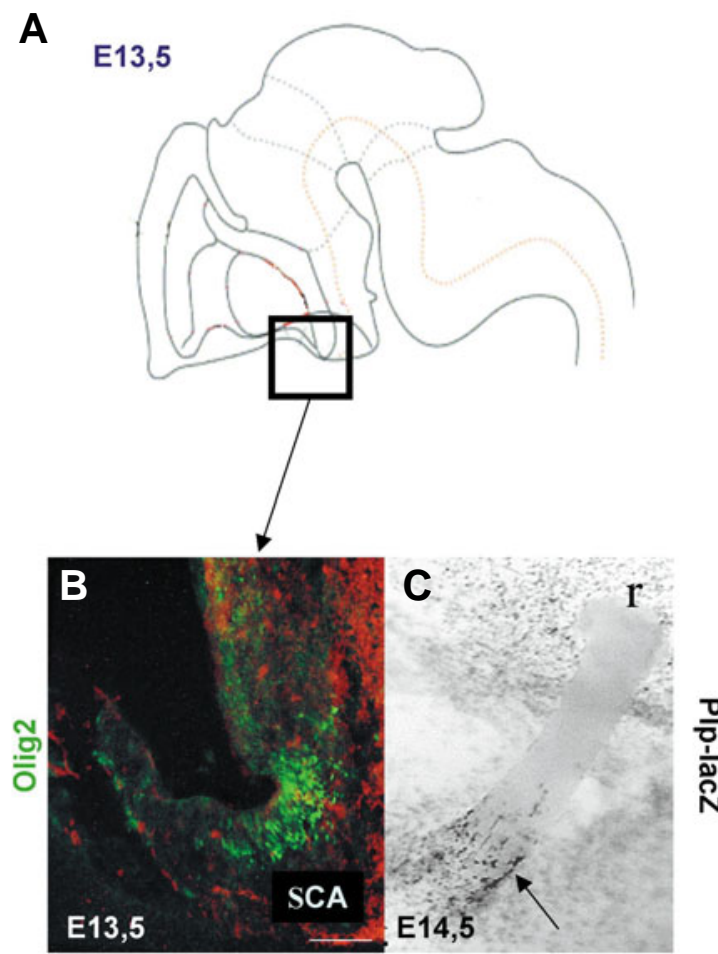
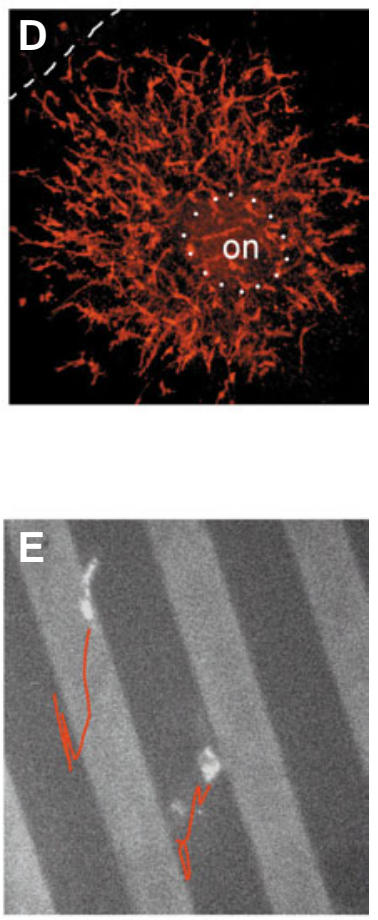

Fig. 5. The embryonic optic nerve: an experimental system for the study of OPC migration. (A) Schematic representation of the mouse brain at E13.5. The boxed area corresponds to the ventral region of the third ventricule, illustrated in (B). (B) Coronal section of E13.5 mouse brain at the level of the third ventricle, immunostained with an anti-Olig2 Ab. OPCs are identified by the expression of Olig2 transcription factor (in green) and localized in the ventricular layer of the suprachiasmatic area. Optic nerve OPCs are generated from these progenitors. (C) Whole-mount X-Gal labeling of the optic nerve of a plp-sh ble-lacZ embryo at E14.5. Note the OPCs (arrow) entering the nerve from the chiasmal region and routing towards the retinal end. (D,E) In vitro systems for analysis of optic nerve OPC migration. (D) Optic nerve explant isolated at E16.5 and cultured in collagen gel. Immunolabeling with the A2B5 antibody, a marker for optic nerve OPCs, shows a radial migration of OPCs around the explant. (E) OPCs isolated from the optic nerve E16.5 plp-GFP embryos were cultured on laminin stripes (in black) versus EphB2-Fc or EphA6-FC or control-Fc coated stripes (in light gray). The migration of two GFP+ OPCs was recorded by time-lapse fluorescent videomicroscopy during 3 to 30 hours (red lines). Scale bar (shown in A): A, $40 \mu \mathrm{m} ; B, 110 \mu \mathrm{m} ; C, 140 \mu \mathrm{m} ; \mathrm{D}, 50 \mu \mathrm{m}$. Reprinted from Spassky et al. (2002), with permission from The Society for Neuroscience. pathfinding and control of cell-cell interactions (Himanen and Nikolov, 2003). A specific feature of these molecules is their ability to elicit bidirectional signalling, that is classical «forward signalling» by the Eph receptor via its intrinsic tyrosine kinase activity and «reverse signalling» by the transmembrane ephrinB ligand via its cytoplasmic domain (Mellitzer et al., 2000). Eph receptors are known to participate in several aspects of the visual system development. They are expressed by retinal ganglion cells and their axonal projections and are key regulators of the retinocollicular mapping (Knoll and Drescher, 2002). We thus questioned whether OPCs could express ephrin ligands able to interact with Eph receptors expressed by axons, during their axonophilic migration in the optic nerve.

We showed the expression of ephrins A5, B2 and B3 in the migrating OPCs of the optic nerve as well as in the diencephalic sites from where they originate (Figure 7 A-D). In addition, we provided evidence that activation of these ligands by immobilized EphA6 or EphB2 receptors increases the adhesion of OPCs on the substrate. In addition, we observed by time-lapse videomicroscopy a strong inhibition of OPC migration on EphB2-Fc substrate, suggesting that ephrinB activation provides regulating signals of OPC migration

Fig. 6. Role of class 3 semaphorins and netrin-1 in the guidance of OPC migration. A schematic representation of the distribution pattern of cells expressing Sema 3A (azur), netrin-1 (orange) and Sema 3F (purple) in the optic nerve and associated structures at E16.5-18.5. The expression of Sema 3A, around the nerve, delineates a clear boundary between the outside and the inside of the nerve, which could force the OPCs to stay within the nerve and migrate along its length. Sema $3 \mathrm{~F}$ is not detected around or inside the ON, but in the retina, including the retinal ganglion cell layer. Sema $3 F$ might thus be synthesized by retinal ganglion cells and transported along the axons to act as a chemoattractant on migrating OPCs. Netrin-1, which is expressed all along the temporal quadrant and in the retinal end of the nerve,

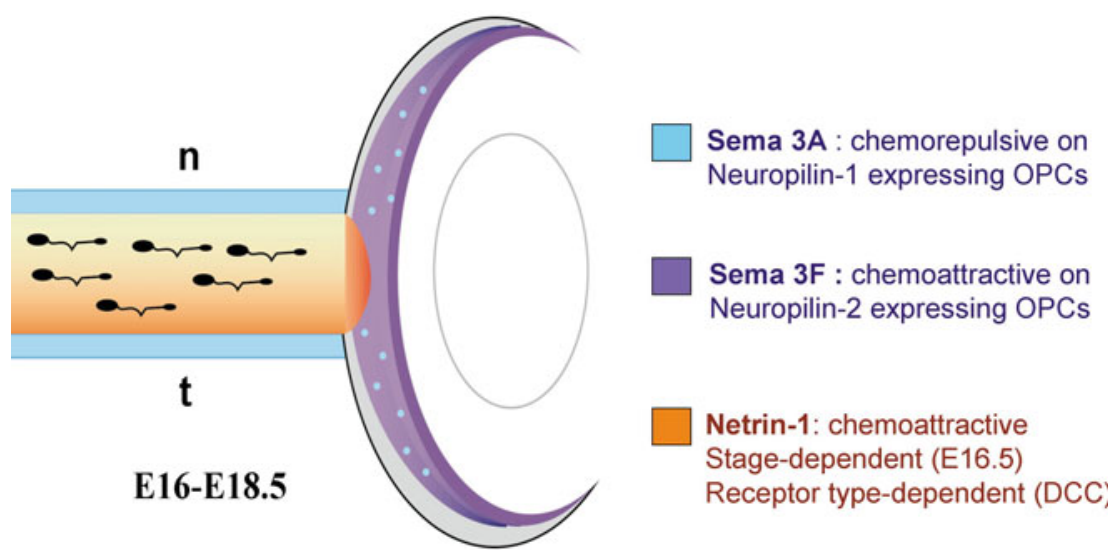
provides a directional cue and facilitates cellular migration of optic nerve OPCs, suggesting that the source of netrin-1 in the retinal papilla guide OPCs towards the optic nerve end and that in the chiasmal region, the temporal source of netrin-1 helps OPCs to enter the nerve from the extramural stream of the ventral diencephalon. n: nasal; t: temporal. Reprinted from Spassky et al. (2002), with permission from The Society for Neuroscience. 
(Figure 7E). Based on these findings, we proposed that OPCs are characterized by an ephrin code and that Eph/ephrin interactions between axon and OPCs contribute to the control of OPC distribution in the optic axonal tracts as well as the progress and arrest of their migration.

\section{Discussion}

Our studies of oligodendrocyte development in the embryonic brain allowed us to identify and define the fate of a population of neural progenitors expressing $p / p / d m-20$. The $p / p$ gene encodes the myelin proteolipid protein in mature oligodendrocytes and, at premyelinating stage, also generates a secreted product promoting oligodendroglial proliferation (Yamada et al., 1999). The $p / p / d m$ 20 progenitors emerge in restricted domains of the ventricular neuroepithelium, localized predominantly ventrally and close to a source of the morphogen Sonic hedgehog. $p / p / d m-20$ ventricular progenitors sequentially generate neurons and oligodendrocytes, being neurogenic from E9.5 in the mouse and oligodendrogenic from E12.5 in the mouse and E5.5 in the chick. p/p/dm-20 expression is maintained only in the oligodendroglial lineage and $p / p$ OPCs can develop into oligodendrocytes independent from PDGFR $\alpha$ signalling. The $p / p / d m-20$ OPCs expand from their ventricular source, predominantly radially in the epicordal regions of the brain and with long range tangential migrations in the forebrain. Notably, the entopeduncalar area, a restricted ventral territory of the caudal telencephalon, appears to be the unique source of OPCs during embryonic development in the chick. The molecular control of $p / p$ OPCs migration was examined in the optic nerve and shown to implicate the secreted guidance proteins, class 3 semaphorins and netrin-1, as well as cell to cell contact molecules, ephrinB2/EphB, which regulate the adhesion of OPCs to their migration substrate. These findings raise four main questions which are discussed below: i) the positional control of the sites of oligodendrogenesis; ii) the link beween neuronal and oligodendroglial lineages; iii) the heterogeneity among OPCs; iiii) the molecular control of OPC migration.

\section{Sites of origin of oligodendrocytes in the embryonic neural tube}

The pioneer experiments on the origin of oligodendrocytes during embryonic development were performed on the rat spinal cord and showed that, before E14, only the ventral portion, but not the dorsal half, can give rise to oligodendrocytes (Warf et al., 1991; Noll and Miller, 1993). This finding has given rise to the concept that oligodendrocytes have a restricted ventral origin. Subsequently, the pattern of expression of a series of markers of oligodendrocyte precursor cells confirmed that the onset of oligodendrogenesis occurred in restricted territories of the ventral neural tube: $P D G F R \alpha$ (Pringle et al., 1993), CNP (Scherer et al., 1994; Yu et al., 1994), plp/dm-20 (Timsit et al., 1995; Spassky et al., 1998; PerezVillegas et al., 1999), the O4-reactive antigen (Ono et al., 1997b), Sox 10 (Kuhlbrodt et al., 1998; Zhou et al., 2000) and Sox 9 (Stolt et al., 2003), Olig1/2 (Lu et al., 2000; Zhou et al., 2000), Nkx2.2 (Xu et al., 2000; Soula et al., 2001; Fu et al., 2002), Sulfatase 1 (Braquart-Varnier et al., 2004). In the spinal cord, the first oligodendrocyte progenitors are generated in bilateral foci localized dorsally to the ventral midline region. In the brain, oligodendrogenesis also starts in paramedian columns of the basal
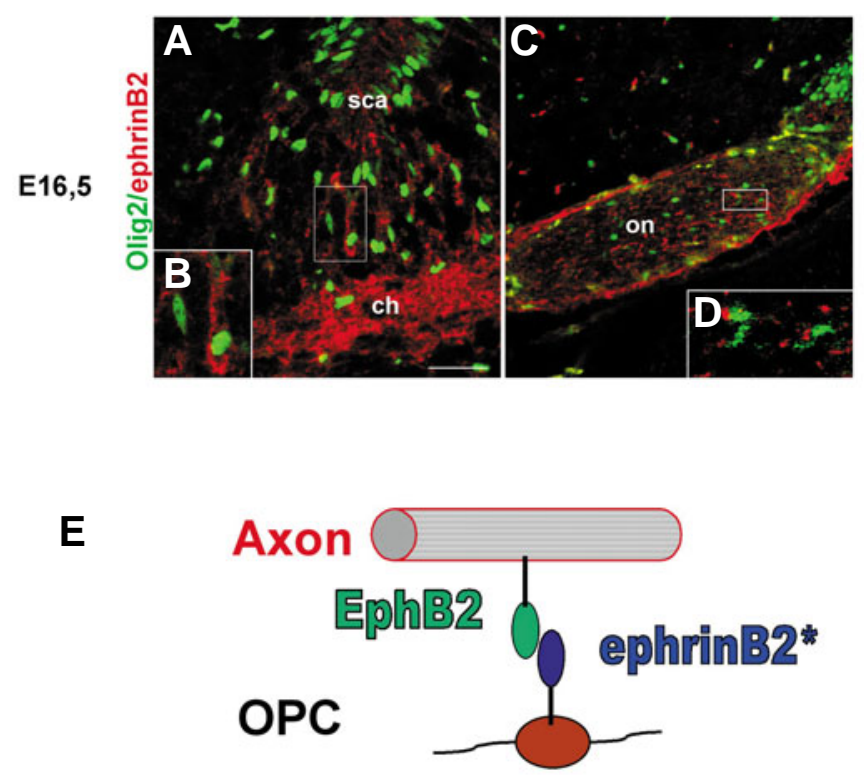

Promoting effect on OPC adhesion

Fig. 7. Role of ephrinB2/EphB interaction in the axonophilic migration of OPCs. (A-D) Brain coronal sections from an E16.5 mouse embryo doubly labeled with anti-ephrinB2 and anti-Olig2 antibodies. In the suprachiasmatic area $(\mathbf{A}, \mathbf{B})$ the two proteins are co-expressed by OPCs. (C,D) Semi-coronal section of the optic nerve. The boxed areas in $(A, C)$ are enlarged in $(B, D)$ respectively, to illustrate the co-expression of Olig2 (green, nuclear staining) and ephrinB2 (red) in the same cell. (E) A schematic model of the contribution of ephrinB2/ephB interactions to the control of axonophilic migration of OPCs in the optic nerve. The ephrinB2 borne at the surface of OPCs is trans-activated by EphB, upon contact with the axons of retinal ganglionic cells. Activation of ephrinB2 has a proadhesive effect on OPCs, the migration of which is subsequently modified and can be either promoted or arrested, depending upon the stability of the ligand-receptor complex interaction. Scale bar (shown in A): A, $50 \mu \mathrm{m} ; B$, $20 \mu \mathrm{m} ; C, 70 \mu \mathrm{m} ; \mathrm{D}, 30 \mu \mathrm{m}$. Reprinted from Prestoz et al. (2004), with permission from Cambridge University Press.

plate of the caudal diencephalon, mesencephalon and rhombencephalon. Exceptions to this juxtamedial position of oligodendrogenic ventricular foci in the ventral neural tube are the medial ganglionic eminence and the entopeduncular area in the alar territory of the forebrain (Olivier et al., 2001; Tekki-Kessaris et al., 2001) and the rhombic lip of the hindbrain (Ono et al., 1997a). However, in all of these sites, oligodendrogenesis is correlated with the expression of the morphogen Sonic hedgehog (Shh), either in the midline (Figure $4 \mathrm{~A}$ ), or within the neuroepithelium of the entopeduncular area and of the rhombic lip. Shh induces various populations of ventral neurons, notably somatic motoneurons (Briscoe and Ericson, 1999), but is also required for oligodendrocyte specification, as shown by gain- and loss of function experiments in the spinal cord (Poncet etal., 1996; Pringle etal., 1996; Orentas et al., 1999; Soula et al., 2001) and in the telencephalon (Nery et al., 2001; Spassky et al., 2001a; Tekki-Kessaris et al., 2001). In addition to the induction of OPC specification, Shh negatively controls the development of astrocytes (Agius et al., 2004). 
Astroglial specification is normally promoted by Bone Morphogenic Proteins (BMPs) (Mehler etal., 2000), which inhibit oligodendrocyte development (Mekki-Dauriac et al., 2002). Therefore, the choice of neuroepithelial progenitors between oligodendroglial and astroglial fate appears to depend upon a balance between the opposite effects of Shh and BMPs.

The possibility that OPCs can derive from other latero-dorsal regions of the brain at later stages of development has also been explored and confirmed by a series of converging data. First, the study of avian chimeras demonstrates a dorsoventral migration of dorsal OPCs, in the thoraco-cervical spinal cord (Cameron-Curry and LeDouarin, 1995). Second, using a Cre-/ox approach to mark different progenitor populations and their complete progeny within the spinal cord of transgenic mice, a minor population of oligodendrocytes was shown to derive from a mediodorsal domain of progenitors expressing $D b \times 1 / D b \times 2$. These later-born oligodendrocytes undergo a restricted migration to populate mainly the dorsolateral white matter (Fogarty et al., 2005). In mice deficient for both $n k \times 6.1$ and 6.2, dorsal oligodendrogenesis was also observed, from E14.5, in the absence of Olig2 progenitors (Cai et al., 2005; Vallstedt et al., 2005; Miller, 2005). Finally, recent work in the mouse spinal cord and telencephalon demonstrates that bFGF can induce, in vitro, the production of oligodendrocytes from Olig2 progenitors (Gabay etal., 2003; Kessaris etal., 2004), suggesting that OPC specification can occur elsewhere than in ventral Olig2 progenitor domains.

Further studies, especially those using Cre-/ox transgenic mice, should soon give a definitive picture of how oligodendrogenesis progresses during the course of neuroepithelial development. Although most of the OPCs of the spinal cord derive from Olig2 progenitors, it is very likely that oligodendrogenesis is not restricted to the ventral Olig2 progenitor domain, but develops sequentially from ventral to dorsal domains of the neural tube. More ventrally, at the margin of the floor plate, the $n k \times 2.2$ domain has also been proposed to generate OPCs (Soula et al., 2001; Fu et al., 2002) and might be the initial site of oligodendrogenesis, due to the proximity of Shh source. Dorsally to the Olig2 domain, the oligodendrogenic potential of neuroepithelium could be expressed at later stages of development, from E14.5 onwards in the mouse, in response to new environmental cues such as bFGF.

\section{Similarities between neuronal and oligodendroglial mechanisms of development}

According to a classical model of cell specification in the neural tube, stem cells give rise to neuroblasts and glioblasts, the latter cells differentiating into either astrocytes or oligodendrocytes. As an archetype of glioblast, the A2B5+ O2A (Oligodendrocyte-type2 Astrocyte) progenitor, extensively studied by the group of M. Raff (Raff et al., 1983; Barres et al., 1992) generates $\mathrm{O4}^{+}$preoligodendrocytes in vitro, but can also give rise to pure populations of astrocytes in the presence of serum. In contrast, it does not produce neurons under normal conditions. Such a type of glioblast progenitor, common for astrocytes and oligodendrocytes, appeared nevertheless hardly detectable in vivo, although recent reports claim that these cells, called GRPs (Glial Restricted Progenitors), could exist in the spinal cord and in the cortex (Noble et al., 2004).

An alternative model of neural cell specification results from a series of converging data obtained during the last five years, which indicates a close relationship between neuronal and oligodendroglial specification. Mechanisms of oligodendrocyte development in vivo show striking similarities to those for neuronal subtypes, including the emergence from localized regions of the neural tube, the involvment of common signalling pathways and downstream transcription factors. For instance, neurons and oligodendrocytes, albeit no astrocytes, differentiate from $p / p / d m-20$ progenitors, as shown in vitro (Figure 2) and in vivo, using a plp-Cre/lox-Rosa26lac $Z$ transgenic line (Delaunay et al., in preparation). Similarly, somatic motor neurons and oligodendrocytes, but no astrocytes, derive from the progenitor domain expressing the basic HelixLoop-Helix (bHLH) transcription factors, Olig1 and Olig2. Both neurons and oligodendrocytes are induced by Shh signalling and inhibited by BMP signalling which rather induces astroglial cells. In addition, unsuspected similarities in transcription factor usage between oligodendrocytes and neurons have been shown. The LIM-HomeoDomain (LIM-HD) gene Nkx2.2 which controls the specification of neuronal identity in the spinal cord and hindbrain (Briscoe et al., 1999; Pattyn et al., 2003) is required for OPC development, at least for the differentiation of OPCs (Fu et al., 2002). The bHLH gene Mash1, required for the neurogenesis in the basal ganglia of the telencephalon (Casarosa et al., 1999), is upregulated during OPC differentiation (Kondo and Raff, 2000). Among others bHLH genes acting in parallel for neuronal and OPC development (Ross et al., 2003), Olig genes have a key role (Rowitch et al., 2002). Olig are required for the development of motor neurons and oligodendrocytes in the developing spinal cord (Lu et al., 2002; Zhou et al., 2002; Takebayachi et al., 2002). Altogether, these similarities in the development of neurons and oligodendrocytes strongly suggest a common intrinsic program of differentiation and the existence of bipotent progenitor cells restricted to a neuronal / oligodendroglial fate. Experimental approaches combining the Cre-lox system and single progenitor cell labeling will probably allow to confirm this hypothesis.

\section{A heterogeneity among the OPCs}

The proliferation, migration and survival of OPCs have previously been shown to require platelet-derived growth factor $A$ (PDGF-A) and its receptor PDGFR- $\alpha$ (Noble etal., 1988; Richarson etal., 1988; Pringle etal., 1993; Fruttiger etal., 1999; Klinghoffer et al., 2002). However, several observations suggest that oligodendrocyte development in vivo requires other growth factors in addition to PDGF-A and that the PDGFR- $\alpha$ OPCs do not represent the overall population of OPCs. First, OPCs accumulate in the hindbrain in the absence of PDGF-A or PDGFR- $\alpha$ signalling (Fruttiger et al., 1999; Klinghoffer et al., 2002). Secondly, we have described the existence of a subpopulation of OPCs in the brain, characterized by the expression of plp/dm-20 (Timsit et al., 1995), which does not express PDGFR- $\alpha$ (Spassky et al., 1998) and does not depend on PDGFR- $\alpha$ signalling for survival and proliferation (Spassky etal., 2001a). These PDGF- $\alpha$-independent OPCs expressing $p / p / d m-20$ are detected in several regions of the embryonic brain prior to the emergence of PDGFR- $\alpha$ expressing cells (Spassky et al., 1998, 2001a, 2002). In addition, after birth, $p / p / d m-20$ OPCs are also distinct from the population of PDGFR- $\alpha$ cells in the subventricular zone of cerebral cortex (Ivanova etal., 2002). This raises the question of the nature of the trophic factor on which the $p / p+$ OPCs depend for their survival and proliferation. Recent investigations strongly suggest that a close member of PDGF family, Vascular endothelial growth factor 
C (VEGF-C), is specifically required for the survival, proliferation and migration of $p / p$ OPCs (LeBras, unpublished data). Two closely related signalling pathways, PDGFR $\alpha$ and VEGFR-3, would thus selectively regulate the development of two distinct populations of oligodendrocyte precursor cells. An additional argument for the diversity of OPCs is the divergence in the intrinsic differential timing of OPCs from different brain regions (Spassky et al., 2001b; Power et al., 2002), consistent with the differing time courses of myelination in these regions. Finally, heterogeneity among OPCs has also been suggested in the adult brain by the presence of functional subpopulations of OPCs in MS lesions (Chang et al., 2002).

A heterogeneity among oligodendrocytes has been suggested by Del Rio-Hortega (1928) and Penfield (1932). On the basis of morphological criteria (size of cell body, number of myelinated internodes, diameter of myelinated axons), these authors have distinguished four sub-groups of oligodendrocytes. More recently, other subpopulations have been described based on biochemical criteria, like expression of members of the collapsin response mediator protein (CRMP) family (Ricard et al., 2001). It has also been observed that subsets of oligodendrocytes are not equally resistant to toxic agents such as cuprizone (Komoly et al., 1987). At present, it is impossible to correlate this morphological and biochemical heterogeneity of the oligodendrocyte population with a specific embryonic origin, dorsal or ventral, or $p / p / d m-20^{+}$or PDGFR $\alpha$. Nevertheless, the presence of different types of OPCs, requiring distinct signalling to develop, should be kept in mind, considering the possible implication in oligodendrocyte pathologies such as MS, where new signalling molecules might be potential therapeutic agents to restore oligodendrocytes.

\section{Molecular control of OPC migration}

During embryonic brain development, the OPCs originate from multiple ventricular foci and migrate along specific pathways (Ono et al., 1997; Olivier et al., 2001). The interaction of OPCs with their environment determines the extent of migration (Olivier et al., 2001), as well as the guidance towards their final position in the brain. Several molecules have already been implicated in the migration and guidance of OPCs. The investigations carried out in the years 90 have demonstrated the role of growth factors and of extra-cellular matrix and integrins signalling molecules in the control of OPC migration. Growth factors, like FGF-2 and PDGFAA secreted along the migratory pathways, have been reported to act as chemotrophic and kinetic factors for OPCs (Armstrong et al., 1990; Milner et al., 1997). Components of the extra-cellular matrix, like tenascin C (Garcion et al., 2001), have been involved in the migration of optic nerve OPCs, while integrins (Milner and ffrench-Constant, 1994) or PSA-NCAM (Wang et al., 1994), were implicated in the axonophilic migration of OPCs observed in the axonal tracts of the white matter and the optic nerve.

Recent studies have proposed new candidates, either secreted factors or contact proteins, in the molecular control of OPC migration. The role of axonal guidance molecules belonging to class 3 semaphorins and netrins has been investigated in the optic nerve and the spinal cord, during embryonic and neonatal periods. Sema 3A repels OPCs (Sugimoto et al., 2001; Spassky et al., 2002; Tsai et al., 2003), while Sema 3F is attractive for those cells (Spassky et al., 2002). The reports on the effect of netrin-1 appear more contradictory (Jarjour et al., 2004). Netrin-
1 was shown to be a repellent for OPCs in the neonatal optic nerve (Sugimoto et al., 2001) and in the embryonic spinal cord (Tsai et al., 2003; Jarjour et al., 2003), wheraes the same factor was attractive for OPCs of the embryonic optic nerve (Spassky et al., 2002). Although it cannot be excluded that differences in the response of OPCs might result from distinct experimental in vitro conditions, the effects of netrin-1 depend, at least in part, upon the type of netrin-1 receptor expressed by the oligodendrocyte. In the optic nerve, around birth, OPCs change their expression of netrin1 receptors, from DCC alone to DCC and Unc5h1. Consequently, the embryonic OPCs are attracted by netrin-1, but after birth OPCs are repelled by this factor (Spassky etal., 2002). Therefore, OPCs express a variety of receptors to class 3 semaphorins and netrin-1 factors, allowing multiple and adaptive responses to the environmental cues found in the course of their migration. This might be related to the presence of different types of OPCs, originating from different ventricular sources. Alternatively, it might indicate that, in the course of ON colonization, OPCs modulate their response to one secreted factor by changing the expression of its specific receptors.

The chemokines, which are secreted signalling molecules that regulate leukocyte migration in a target-specific fashion (Baggiolini, 1998), have also been implicated in the control of OPC migration. Especially, the CXCL1 ligand stimulates the proliferation of spinal cord OPCs in synergy with PDGF-AA (Wu et al., 2000). This chemokine inhibits the migration of OPCs through activation of its receptor CXCR2 and has been proposed as a stop and patterning signal for OPCs in the neonatal spinal cord (Tsai etal., 2002). The participation of others members of this family to the migration of OPCs in the brain is moreover very likely (M. Dubois-Dalcq, personal communication).

The migration of OPCs appears also, to some extent, axonophilic, as best documented by the invasion of the optic nerve, where OPCs migrate in a highly enriched axonal environment. In this context of intercellular contact molecules, the role of ephrins and their Eph receptors had not been examined until our study (Prestoz et al., 2004). We showed that ephrinB2 ligand was expressed by OPCs and induced dramatic changes in the adhesion and migration of OPCs on their substrate, upon contact and activation by EphB receptors. We thus proposed that the Eph/ephrin interactions between axons and migrating OPCs determine a recognition code controlling the progress or the arrest of OPC migration. EphB/ephrinB interaction has been reported to induce cell-cell or cell-matrix repulsion. This effect is associated with a loss of polymerized F-actin structures and a disassembly of focal adhesions (Cowan and Henkemeyer, 2001) and is dependent of endocytosis of EphB/ephrinB complexes at the cell surface. Endocytosis is necessary and sufficient to promote termination of adhesion, cell detachment and further cell repulsion (Zimmer et al., 2003). In particular, blocking endocytosis through C-terminal truncation of either EphB2 or ephrinB1, or both molecules, results in a switch from a repulsive effect of ephrinB1 activation to an attractive effect and a cell detachment. The progress or halt of OPC migration could therefore be linked to the control of EphB-ephrinB bi-directional endocytosis. Such a regulation would explain how migrating OPC stop and fix at the contact of the axon they will myelinate later in development.

Finally, the molecules that influence the migration of OPCs include a combination of short-range attractants and repellents 
and long-range chemoattractants and chemorepellents. The role of each of these factors can differ during the course of development and between brain territories, probably due to changes in the receptor repertoire of OPCs and to environmental co-factors. To date, the participation of these ligands and their specific receptors in oligodendrocyte diseases, like MS, has not been reported. Studies on MS plaques and demyelinated animal models have nevertheless started and will most likely confirm the importance of these molecules in the maintenance and repair of oligodendroglial populations in the adult. A synthetic view of the molecular control of oligodendrocyte migrations is therefore a challenging issue for further therapeutic developments against demyelinating pathologies.

\section{Acknowledgements}

This work was supported by The Institut National de la Santé et de la Recherche Médicale, the Ministère de l'Education Nationale et de la Recherche (ACl Biologie du Développement), the European Community (BMH4-CT96-0249 and QLG3-CT-2000-015556) and by grants from the Association de Recherche sur la Sclérose en Plaques, the European Leucodistrophy Association, the Association pour la Recherche contre le Cancer. B.L.B was a fellow of the Ministère de l'Education Nationale et de la Recherche, of the Fondation pour la Recherche Médicale and of the Ligue FranÁaise contre la Sclérose en Plaques.

\section{References}

AGIUS, E., SOUKKARIEH, C., DANESIN, C., KAN, P., TAKEBAYASHI, H., SOULA, C. AND COCHARD, P. (2004). Converse control of oligodendrocyte and astrocyte lineage development by Sonic hedgehog in the chick spinal cord. Dev Biol 270, 308-21.

ARMSTRONG, R. C., HARVATH, L. AND DUBOIS-DALCQ, M. E. (1990). Type 1 astrocytes and oligodendrocyte-type 2 astrocyte glial progenitors migrate toward distinct molecules. J Neurosci Res 27, 400-7.

BAGGIOLINI, M. (1998). Chemokines and leukocyte traffic. Nature 392, 565-8.

BARRES, B. A., HART, I. K., COLES, H. S., BURNE, J. F., VOYVODIC, J. T., RICHARDSON, W. D. AND RAFF, M. C. (1992). Cell death and control of cell survival in the oligodendrocyte lineage. Cell 70, 31-46.

BRAQUART-VARNIER, C., DANESIN, C., CLOUSCARD-MARTINATO, C., AGIUS, E., ESCALAS, N., BENAZERAF, B., Al, X., EMERSON, C., COCHARD, P. AND SOULA, C. (2004). A subtractive approach to characterize genes with regionalized expression in the gliogenic ventral neuroepithelium: identification of chick sulfatase 1 as a new oligodendrocyte lineage gene. Mol Cell Neurosci 25, 612-28.

BRISCOE, J. AND ERICSON, J. (1999). The specification of neuronal identity by graded Sonic Hedgehog signalling. Semin Cell Dev Biol 10, 353-62.

BRISCOE, J., SUSSEL, L., SERUP, P., HARTIGAN-O'CONNOR, D., JESSELL, T. M., RUBENSTEIN, J. L. AND ERICSON, J. (1999). Homeobox gene Nkx2.2 and specification of neuronal identity by graded Sonic hedgehog signalling. Nature 398, 622-7.

CAI, J., QI, Y., HU, X., TAN, M., LIU, Z., ZHANG, J., LI, Q., SANDER, M. and QIU, M. (2005) Generation of oligodendrocyte precursor cells from mouse dorsal spinal cord independent of Nkx6 regulation and Shh signaling. Neuron 45: 4153.

CURRY, P. AND LE DOUARIN, N. M. (1995). Oligodendrocyte precursors originate from both the dorsal and the ventral parts of the spinal cord. Neuron 15, 1299310.

CAMERON-CURRY, P. AND LE DOUARIN, N. M. (1995). Oligodendrocyte precursors originate from both the dorsal and the ventral parts of the spinal cord. Neuron 15, 1299-310.

CASAROSA, S., FODE, C. AND GUILLEMOT, F. (1999). Mash1 regulates neurogenesis in the ventral telencephalon. Development 126, 525-34.

CHANG, A., TOURTELLOTTE, W. W., RUDICK, R. AND TRAPP, B. D. (2002). Premyelinating oligodendrocytes in chronic lesions of multiple sclerosis. NEng/ J Med 346, 165-73.
COWAN, C. A. AND HENKEMEYER, M. (2001). The SH2/SH3 adaptor Grb4 transduces B-ephrin reverse signals. Nature 413, 174-9.

DEL RIO-HORTEGA, P. (1928). Tercera aportation al conocimiento morfologica e interpretacion functional de la oligodendroglia. Mem Real Soc Expan Hist Nat 14, 5-122.

DICKINSON,P.J., FANARRAGA, M. L., GRIFFITHS, I. R., BARRIE, J. M., KYRIAKIDES, E. AND MONTAGUE, P. (1996). Oligodendrocyte progenitors in the embryonic spinal cord express DM-20. Neuropathol App/ Neurobiol 22, 188-98.

EICKHOLT, B. J., MACKENZIE, S. L., GRAHAM, A., WALSH, F. S. AND DOHERTY, P. (1999). Evidence for collapsin-1 functioning in the control of neural crest migration in both trunk and hindbrain regions. Development 126, 2181-9.

FOGARTY, M., RICHARDSON, W.D. and KESSARIS, N. (2005) A subset of oligodendrocytes generated from radial glia in the dorsal spinal cord. Development 132: 1951-9.

FRUTTIGER, M., KARLSSON, L., HALL, A. C., ABRAMSSON, A., CALVER, A. R., BOSTROM, H., WILLETTS, K., BERTOLD, C. H., HEATH, J. K., BETSHOLTZ, C. ET AL. (1999). Defective oligodendrocyte development and severe hypomyelination in PDGF-A knockout mice. Development 126, 457-67.

FU, H., QI, Y., TAN, M., CAI, J., TAKEBAYASHI, H., NAKAFUKU, M., RICHARDSON, W. AND QIU, M. (2002). Dual origin of spinal oligodendrocyte progenitors and evidence for the cooperative role of Olig2 and Nkx2.2 in the control of oligodendrocyte differentiation. Development 129, 681-93.

GABAY, L., LOWELL, S., RUBIN, L. L. AND ANDERSON, D. J. (2003). Deregulation of dorsoventral patterning by FGF confers trilineage differentiation capacity on CNS stem cells in vitro. Neuron 40, 485-99.

GARCION, E., FAISSNER, A. AND FFRENCH-CONSTANT, C. (2001). Knockout mice reveal a contribution of the extracellular matrix molecule tenascin-C to neural precursor proliferation and migration. Development 128, 2485-96.

GOSHIMA, Y., ITO, T., SASAKI, Y. AND NAKAMURA, F. (2002). Semaphorins as signals for cell repulsion and invasion. J Clin Invest 109, 993-8.

HIMANEN, J. P. AND NIKOLOV, D. B. (2003). Eph signaling: a structural view. Trends Neurosci 26, 46-51.

IVANOVA, A., NAKAHIRA, E., KAGAWA, T., OBA, A., WADA, T., TAKEBAYASHI, H., SPASSKY, N., LEVINE, J., ZALC, B., IKENAKA, K. (2003) Evidence for a second wave of oligodendrogenesis in the postnatal cerebral cortex of the mouse. J Neurosci Res. 73, 581-92

JARJOUR, A. A. AND KENNEDY, T. E. (2004). Oligodendrocyte precursors on the move: mechanisms directing migration. Neuroscientist 10, 99-105.

JARJOUR, A. A., MANITT, C., MOORE, S. W., THOMPSON, K. M., YUH, S. J. AND KENNEDY, T. E. (2003). Netrin-1 is a chemorepellent for oligodendrocyte precursor cells in the embryonic spinal cord. J Neurosci 23, 3735-44.

KESSARIS, N., JAMEN, F., RUBIN, L. L. AND RICHARDSON, W. D. (2004). Cooperation between sonic hedgehog and fibroblast growth factor/MAPK signalling pathways in neocortical precursors. Development 131, 1289-98.

KITAGAWA, K., SINOWAY, M. P., YANG, C., GOULD, R. M. AND COLMAN, D. R. (1993). A proteolipid protein gene family: expression in sharks and rays and possible evolution from an ancestral gene encoding a pore-forming polypeptide. Neuron 11, 433-48.

KLINGHOFFER, R. A., HAMILTON, T. G., HOCH, R. AND SORIANO, P. (2002). An allelic series at the PDGF $\alpha R$ locus indicates unequal contributions of distinct signaling pathways during development. Dev Cell 2, 103-13.

KNOLL, B. AND DRESCHER, U. (2002). Ephrin-As as receptors in topographic projections. Trends Neurosci 25, 145-9.

KOMOLY, S., JEYASINGHAM, M. D., PRATT, O. E. AND LANTOS, P. L. (1987). Decrease in oligodendrocyte carbonic anhydrase activity preceding myelin degeneration in cuprizone induced demyelination. J Neurol Sci 79, 141-8.

KONDO, T. AND RAFF, M. (2000). Basic helix-loop-helix proteins and the timing of oligodendrocyte differentiation. Development 127, 2989-98.

KUHLBRODT, K., HERBARTH, B., SOCK, E., HERMANS-BORGMEYER, I. AND WEGNER, M. (1998). Sox10, a novel transcriptional modulator in glial cells. $J$ Neurosci 18, 237-50.

LE DOUARIN N. (1969). Particularités du noyau interphasique chez la caille japonaise (Coturnix coturnix japonica). Utilisation de ces particularités comme marquage biologique dans les recherches sur les interactions tissulaires et les migrations cellulaires au cours de l'ontogénèse. Bull. Soc. Fr. Belg. 103, 435452. 
LE DOUARIN, N. M. (1993). Embryonic neural chimaeras in the study of brain development. Trends Neurosci 16, 64-72.

LEES, M. AND BROSTOFF, S. (1984). Proteins of myelin. In Myelin, (ed. P. Morell), pp. 197-224. New-York: Plenum.

LU, Q. R., SUN, T., ZHU, Z., MA, N., GARCIA, M., STILES, C. D. AND ROWITCH, D. H. (2002). Common developmental requirement for Olig function indicates a motor neuron/oligodendrocyte connection. Cel/ 109, 75-86.

LU, Q. R., YUK, D., ALBERTA, J. A., ZHU, Z., PAWLITZKY, I., CHAN, J., MCMAHON, A. P., STILES, C. D. AND ROWITCH, D. H. (2000). Sonic hedgehog-regulated oligodendrocyte lineage genes encoding bHLH proteins in the mammalian central nervous system. Neuron 25, 317-29.

MEHLER, M. F., MABIE, P. C., ZHU, G., GOKHAN, S. AND KESSLER, J. A. (2000). Developmental changes in progenitor cell responsiveness to bone morphogenetic proteins differentially modulate progressive CNS lineage fate. Dev Neurosci 22, 74-85.

MEKKI-DAURIAC, S., AGIUS, E., KAN, P. AND COCHARD, P. (2002). Bone morphogenetic proteins negatively control oligodendrocyte precursor specification in the chick spinal cord. Development 129, 5117-30.

MELLITZER, G., XU,'QQ. AND WILKINSON, D. G. (1999). Eph receptors and ephrins restrict cell intermingling and communication. Nature 400, 77-81.

MESSERSMITH, E. K., LEONARDO, E. D., SHATZ, C. J., TESSIER-LAVIGNE, M., GOODMAN, C. S. AND KOLODKIN, A. L. (1995). Semaphorin III can function as a selective chemorepellent to pattern sensory projections in the spinal cord. Neuron 14, 949-59.

MILLER, R.H. (2005) Dorsally derived oligodendrocytes come of age. Neuron 45: 1-3.

MILNER, R. ANDERSON, H. J., RIPPON, R. F., MCKAY, J. S., FRANKLIN, R. J., MARCHIONNI, M. A., REYNOLDS, R. AND FFRENCH-CONSTANT, C. (1997). Contrasting effects of mitogenic growth factors on oligodendrocyte precursor cell migration. Glia 19, 85-90.

MILNER, R. AND FFRENCH-CONSTANT, C. (1994). A developmental analysis of oligodendroglial integrins in primary cells: changes in $\alpha \mathrm{v}$-associated $\beta$ subunits during differentiation. Development 120, 3497-506.

NERY, S., WICHTERLE, H. AND FISHELL, G. (2001). Sonic hedgehog contributes to oligodendrocyte specification in the mammalian forebrain. Development 128, 527-40.

NOBLE, M., MURRAY, K., STROOBANT, P., WATERFIELD, M. D. AND RIDDLE, P. (1988). Platelet-derived growth factor promotes division and motility and inhibits premature differentiation of the oligodendrocyte/type-2 astrocyte progenitor cell. Nature 333, 560-2.

NOBLE, M., PROSCHEL, C. AND MAYER-PROSCHEL, M. (2004). Getting a GR(i)P on oligodendrocyte development. Dev Biol 265, 33-52.

NOLL, E. AND MILLER, R. H. (1993). Oligodendrocyte precursors originate at the ventral ventricular zone dorsal to the ventral midline region in the embryonic rat spinal cord. Development 118, 563-73.

OLIVIER, C., COBOS, I., PEREZ VILLEGAS, E. M., SPASSKY, N., ZALC, B., MARTINEZ, S. AND THOMAS, J. L. (2001). Monofocal origin of telencephalic oligodendrocytes in the anterior entopeduncular area of the chick embryo. Development 128, 1757-69.

ONO, K., FUJISAWA, H., HIRANO, S., NORITA, M., TSUMORI, T. AND YASUI, Y. (1997a). Early development of the oligodendrocyte in the embryonic chick metencephalon. J Neurosci Res 48, 212-25.

ONO, K., YASUI, Y., RUTISHAUSER, U. AND MILLER, R. H. (1997b). Focal ventricular origin and migration of oligodendrocyte precursors into the chick optic nerve. Neuron 19, 283-92.

ORENTAS, D. M., HAYES, J. E., DYER, K. L. AND MILLER, R. H. (1999). Sonic hedgehog signaling is required during the appearance of spinal cord oligodendrocyte precursors. Development 126, 2419-29.

PATTYN, A., VALLSTEDT, A., DIAS, J. M., SANDER, M. AND ERICSON, J. (2003). Complementary roles for Nkx6 and Nkx2 class proteins in the establishment of motoneuron identity in the hindbrain. Development 130, 4149-59.

PENFIELD, W. (1932). Neuroglia: normal and pathological. In Cytology and cellular pathology of the nervous system, vol. 2, pp. 437-443. New-york: Hoeber.

PEREZ VILLEGAS, E. M., OLIVIER, C., SPASSKY, N., PONCET, C., COCHARD, P., ZALC, B., THOMAS, J. L. AND MARTINEZ, S. (1999). Early specification of oligodendrocytes in the chick embryonic brain. Dev Biol 216, 98-113.
PFRIEGER, F. W. AND BARRES, B. A. (1995). What the fly's glia tell the fly's brain Cell 83, 671-674.

PONCET, C., SOULA, C., TROUSSE, F., KAN, P., HIRSINGER, E., POURQUIE, O. DUPRAT, A. M. AND COCHARD, P. (1996). Induction of oligodendrocyte progenitors in the trunk neural tube by ventralizing signals: effects of notochord and floor plate grafts and of sonic hedgehog. Mech Dev 60, 13-32.

POPOT, J. L., PHAM DINH, D. AND DAUTIGNY, A. (1991). Major myelin proteolipid: the 4- $\alpha$-helix topology. J Membr Biol 123, 278.

POWER, J., MAYER-PROSCHEL, M., SMITH, J. AND NOBLE, M. (2002) Oligodendrocyte precursor cells from different brain regions express divergent properties consistent with the differing time courses of myelination in these regions. Dev Biol 245, 362-75.

PRESTOZ, L., CHATZOPOULOU, E., LEMKINE, G., SPASSKY, N., LE BRAS, B., KAGAWA, T., IKENAKA, K., ZALC, B. AND THOMAS, J. L. (2004). Control o axonophilic migration of oligodendrocyte precursor cells by Eph-ephrin interaction. Neuron Glia Biology 1, 73-83.

PRINGLE, N. P. AND RICHARDSON, W. D. (1993). A singularity of PDGF alphareceptor expression in the dorsoventral axis of the neural tube may define the origin of the oligodendrocyte lineage. Development 117, 525-33

PRINGLE, N. P., YU, W. P., GUTHRIE, S., ROELINK, H., LUMSDEN, A., PETERSON, A. C. AND RICHARDSON, W. D. (1996). Determination of neuroepithelial cell fate: induction of the oligodendrocyte lineage by ventral midline cells and sonic hedgehog. Dev Bio/177, 30-42.

RAFF, M. C., MILLER, R. H. AND NOBLE, M. (1983). Glial cell lineages in the rat optic nerve. Cold Spring Harb Symp Quant Biol 48 PT 2, 569-72.

RAPER, J. A. (2000). Semaphorins and their receptors in vertebrates and invertebrates. Curr Opin Neurobiol 10, 88-94.

RICARD, D., ROGEMOND, V., CHARRIER, E., AGUERA, M., BAGNARD, D., BELIN, M. F., THOMASSET, N. AND HONNORAT, J. (2001). Isolation and expression pattern of human Unc-33-like phosphoprotein 6/collapsin response mediator protein 5 (Ulip6/CRMP5): coexistence with Ulip2/CRMP2 in Sema3asensitive oligodendrocytes. J Neurosci 21, 7203-14.

RICHARDSON, W. D., PRINGLE, N., MOSLEY, M. J., WESTERMARK, B. AND DUBOIS-DALCQ, M. (1988). A role for platelet-derived growth factor in normal gliogenesis in the central nervous system. Cell 53, 309-19.

ROSS, S. E., GREENBERG, M. E. AND STILES, C. D. (2003). Basic helix-loophelix factors in cortical development. Neuron 39, 13-25.

ROWITCH, D. H., LU, Q. R., KESSARIS, N. AND RICHARDSON, W. D. (2002). An 'oligarchy' rules neural development. Trends Neurosci 25, 417-22.

SCHERER, S. S., BRAUN, P. E., GRINSPAN, J., COLLARINI, E., WANG, D. Y AND KAMHOLZ, J. (1994). Differential regulation of the 2',3'-cyclic nucleotide 3 '-phosphodiesterase gene during oligodendrocyte development. Neuron 12 1363-75.

SERAFINI, T., KENNEDY, T. E., GALKO, M. J., MIRZAYAN, C., JESSELL, T. M. AND TESSIER-LAVIGNE, M. (1994). The netrins define a family of axon outgrowthpromoting proteins homologous to C. elegans UNC-6. Cell 78, 409-24.

SMALL, R. K., RIDDLE, P. AND NOBLE, M. (1987). Evidence for migration of oligodendrocyte-type-2 astrocyte progenitor cells into the developing rat optic nerve. Nature 328, 155-7.

SOULA, C., DANESIN, C., KAN, P., GROB, M., PONCET, C. AND COCHARD, P. (2001). Distinct sites of origin of oligodendrocytes and somatic motoneurons in the chick spinal cord: oligodendrocytes arise from Nkx2.2-expressing progenitors by a Shh-dependent mechanism. Development 128, 1369-79.

SPASSKY, N., DE CASTRO, F., LE BRAS, B., HEYDON, K., QUERAUD-LESAUX, F., BLOCH-GALLEGO, E., CHEDOTAL, A., ZALC, B. AND THOMAS, J. L. (2002). Directional guidance of oligodendroglial migration by class 3 semaphorins and netrin-1. J Neurosci 22, 5992-6004.

SPASSKY, N., GOUJET-ZALC, C., PARMANTIER, E., OLIVIER, C., MARTINEZ, S., IVANOVA, A., IKENAKA, K., MACKLIN, W., CERRUTI, I., ZALC, B. ET AL. (1998). Multiple restricted origin of oligodendrocytes. JNeurosci 18, 8331-43.

SPASSKY, N., HEYDON, K., MANGATAL, A., JANKOVSKI, A., OLIVIER, C., QUERAUD-LESAUX, F., GOUJET-ZALC, C., THOMAS, J. L. AND ZALC, B. (2001a). Sonic hedgehog-dependent emergence of oligodendrocytes in the telencephalon: evidence for a source of oligodendrocytes in the olfactory bulb that is independent of PDGFR $\alpha$ signaling. Development 128, 4993-5004. 
SPASSKY, N., OLIVIER, C., COBOS, I., LEBRAS, B., GOUJET-ZALC, C., MARTINEZ, S., ZALC, B. AND THOMAS, J. L. (2001b). The early steps of oligodendrogenesis: insights from the study of the plp lineage in the brain of chicks and rodents. Dev Neurosci 23, 318-26.

STOLT, C. C., LOMMES, P., SOCK, E., CHABOISSIER, M. C., SCHEDL, A. AND WEGNER, M. (2003). The Sox9 transcription factor determines glial fate choice in the developing spinal cord. Genes Dev 17, 1677-89.

SUGIMOTO, Y., TANIGUCHI, M., YAGI, T., AKAGI, Y., NOJYO, Y. AND TAMAMAKI, N. (2001). Guidance of glial precursor cell migration by secreted cues in the developing optic nerve. Development 128, 3321-30.

TAKEBAYASHI, H., NABESHIMA, Y., YOSHIDA, S., CHISAKA, O. AND IKENAKA, K. (2002). The basic helix-loop-helix factor olig2 is essential for the development of motoneuron and oligodendrocyte lineages. Curr Biol 12, 1157-63.

TEKKI-KESSARIS, N., WOODRUFF, R., HALL, A. C., GAFFIELD, W., KIMURA, S., STILES, C. D., ROWITCH, D. H. AND RICHARDSON, W. D. (2001). Hedgehogdependent oligodendrocyte lineage specification in the telencephalon. Development 128, 2545-54.

TIMSIT, S., MARTINEZ, S., ALLINQUANT, B., PEYRON, F., PUELLES, L. AND ZALC, B. (1995). Oligodendrocytes originate in a restricted zone of the embryonic ventral neural tube defined by DM-20 mRNA expression. JNeurosci 15, 1012-24.

TIMSIT, S. G., BALLY-CUIF, L., COLMAN, D. R. AND ZALC, B. (1992). DM-20 mRNA is expressed during the embryonic development of the nervous system of the mouse. J Neurochem 58, 1172-5.

TSAI, H. H., FROST, E., TO, V., ROBINSON, S., FFRENCH-CONSTANT, C., GEERTMAN, R., RANSOHOFF, R. M. AND MILLER, R.H. (2002). The chemokine receptor CXCR2 controls positioning of oligodendrocyte precursors in developing spinal cord by arresting their migration. Cell 110, 373-83.

TSAI, H. H., TESSIER-LAVIGNE, M. AND MILLER, R. H. (2003). Netrin 1 mediates spinal cord oligodendrocyte precursor dispersal. Development 130, 2095-105.

VALLSTEDT, A., KLOS, J.M. and ERICSON, J. (2005) Multiple dorsoventral origins of oligodendrocyte generation in the spinal cord and hindbrain. Neuron 45: 55-67.

WANG, C., ROUGON, G. AND KISS, J. Z. (1994). Requirement of polysialic acid for the migration of the O-2A glial progenitor cell from neurohypophyseal explants. JNeurosci 14, 4446-57.
WARF, B. C., FOK-SEANG, J. AND MILLER, R. H. (1991). Evidence for the ventral origin of oligodendrocyte precursors in the rat spinal cord. JNeurosci $11,2477-88$.

WIGHT, P. A., DUCHALA, C. S., READHEAD, C. AND MACKLIN, W. B. (1993). A myelin proteolipid protein-LacZ fusion protein is developmentally regulated and targeted to the myelin membrane in transgenic mice. J Cel/ Bio/ 123, 44354.

WILKINSON, D. G. (2001). Multiple roles of EPH receptors and ephrins in neural development. Nat Rev Neurosci 2, 155-64.

WU, Q., MILLER, R. H., RANSOHOFF, R. M., ROBINSON, S., BU, J. AND NISHIYAMA, A. (2000). Elevated levels of the chemokine GRO-1 correlate with elevated oligodendrocyte progenitor proliferation in the jimpy mutant. $J$ Neurosci 20, 2609-17.

XU, X., CAI, J., FU, H., WU, R., QI, Y., MODDERMAN, G., LIU, R. AND QIU, M. (2000). Selective expression of Nkx-2.2 transcription factor in chicken oligodendrocyte progenitors and implications for the embryonic origin of oligodendrocytes. Mol Cell Neurosci 16, 740-53.

YAMADA, M., IVANOVA, A., YAMAGUCHI, Y., LEES,M.B., IKENAKA, K. (1999) Proteolipid protein gene product can be secreted and exhibit biological activity during early development. J Neurosci.19, 2143-51.

YAN, Y., LAGENAUR, C. AND NARAYANAN, V. (1993). Molecular cloning of M6: identification of a PLP/DM20 gene family. Neuron 11, 423-31.

YU, W. P., COLLARINI, E. J., PRINGLE, N. P. AND RICHARDSON, W. D. (1994). Embryonic expression of myelin genes: evidence for a focal source of oligodendrocyte precursors in the ventricular zone of the neural tube. Neuron $12,1353-62$.

ZHOU, Q. AND ANDERSON, D. J. (2002). The bHLH transcription factors OLIG2 and OLIG1 couple neuronal and glial subtype specification. Cel/ 109, 61-73.

ZHOU, Q., WANG, S. AND ANDERSON, D. J. (2000). Identification of a novel family of oligodendrocyte lineage-specific basic helix-loop-helix transcription factors. Neuron 25, 331-43.

ZIMMER, M., PALMER, A., KOHLER, J. AND KLEIN, R. (2003). EphB-ephrinB bi-directional endocytosis terminates adhesion allowing contact mediated repulsion. Nat Cel/ Biol 5, 869-78. 